\title{
DIVISION II / WORKING GROUP INTERNATIONAL COLLABORATION IN SPACE WEATHER
}

\author{
CHAIR \\ MEMBERS
}

\author{
David F. Webb \\ Nat Gopalswamy, William Liu, \\ David G. Sibeck, Brigitte Schmieder, \\ Jingxiu Wang, Chi Wang
}

\section{PROCEEDINGS BUSINESS MEETING on 24 August 2006}

\section{Introduction}

The IAU Division II WG on International Collaboration in Space Weather has as its main goal to help coordinate the many activities related to space weather at an international level. The WG currently includes the international activities of the International Heliospheric Year (IHY), the International Living with a Star (ILWS) program, the CAWSES (Climate and Weather of the Sun-Earth System) Working Group on Sources of Geomagnetic Activity, and Space Weather Studies in China. The coordination of IHY activities within the IAU is led by Division II under this working group. The focus of this half-day meeting was on the activities of the IHY program. About 20 people were in attendance. The Chair of the WG, David F. Webb, gave a brief introduction noting that the meeting would have two parts: first, a session on IHY activities emphasizing IHY Regional coordination and, second, a general discussion of the other programs of the WG involving international Space Weather activities.

\section{IHY activities}

The International Heliospheric Year is an international program of scientific collaboration being planned for 2007, the 50th anniversary of the International Geophysical Year. The physical realm of the IHY encompasses all of the solar system out to the interstellar medium. The main IHY site is: <http://ihy2007.org. Nat Gopalswamy is the Chair of the IHY subgroup, and David Webb is the IAU representative for the IHY. Four key activities are being promoted under the IHY program: science activities, the UN Basic Space Sciences (UNBSS) initiative, IGY Gold, and Public outreach activities. The science activities are centered around Coordinated Investigation Programs (CIPs), campaigns on focused topics of heliophysical interest in 20072008. The CIPs will involve many instruments from space and from the ground around the world. The United Nations IHY effort is being led by Hans Haubold under the UNBSS program. The UNBSS activities include deployment of scientific instruments in developing nations for space science investigations by scientists from developed nations and annual workshops. The IGY Gold program recognizes scientists around the world who worked for IGY programs in 1957. Public outreach activities include spreading knowledge of space science and exploration to the public and inspiring the next generation of space scientists. The IHY was discussed in Special Session 5 at the Prague GA on 22 August 2006 on support for astronomy education and research in developing countries.

As chair of the WG's IHY subgroup, Nat Gopalswamy gave an overview of the current status of IHY activities. He gave a dedication to the memory of Professor James van Allen, the U.S. space pioneer who died recently. Gopalswamy noted that the IHY consolidates the 50 years of achievements in Space Science following the IGY in 1957 into a knowledge base called Heliophysics. The new word Heliophysics reflects the extension of Geophysics to the current physical scale of in situ investigations. Other daughters of the IGY include Global Geological Campaigns under the International Year of Planet Earth (IYPE), the Third International Polar Year (IPY), and the Electronic Geophysical Year (eGY). IHY has cooperative programs with each of these 
*HY's. As the IAU Representative for SCOSTEP, Gopalswamy discussed SCOSTEP activities related to IHY, especially its Climate And Weather of the Sun-Earth System (CAWSES) program which runs from 2004-2008.

The IHY is organized into seven regions worldwide. The coordinators of three of these regions that were in attendance described IHY activities in their region. Jean-Louis Bougeret (with C. Briand), Europe, noted that this region has representatives in about 20 countries. They had their first General Assembly in Paris in January, 2006 and the proceedings have been published. The 2nd European GA is being organized by the Italian Committee (Chair, E. Antonucci) to be held in Torino, Italy, 18-22 June 2007. European IHY activities include developing a DVD about IHY-related scientific topics in three parts: The Heliosphere, The Aurorae, and Space Probes, having an "Open Doors Day" on June 10, 2007, and having science competitions for secondary schools. At the national level activities are being planned in the Czech Republic, Belgium, France, Germany, Ireland, Italy, Bulgaria, Spain, and Turkey/Balkans.

C. Mandrini (with J.-P. Raulin), Latin America, presented the many IHY activities being planned there. The most active countries are Argentina, Brazil, Peru and Mexico. Fourteen institutions are involved in national observatories, national research institutes, laboratories and/or university departments, and 47 principal investigators and their accompanying research groups are involved in instrumentation or observations. IHY Scientific Disciplines include: 1) the Heliosphere and Cosmic Rays: modulation of cosmic rays by the Sun, detection of solar neutrons during large flares, detection and imaging of large-scale solar wind disturbances, and early detection of solar events; 2) Solar Physics: flares, CMEs, active regions, particle acceleration, radiation mechanisms (optical and radio wavelengths); 3) Planetary Ionospheres, Thermospheres, Mesospheres and Climate studies: Ionosphere studies- D-region perturbations, equatorial and mid-latitude quiet and perturbed ionosphere, ionospheric plasma instabilities; and 4) Geomagnetism: Earth magnetic field measurements, South Atlantic magnetic anomaly monitoring, solar induced geomagnetic activity. Regional planning meetings were held in Sao Paulo, Brazil in December 2005, during the SCOSTEP 11th Quadrennial Solar Terrestrial Physics Symposium in Rio de Janerio, Brazil in March 2006, and in Puerto Vallarta, Mexico, November 2006. The region has five CIP programs, and is supporting the SAVnet and SAMA UNBSS programs and is proposing a magnetometer network at the IHY-UNBSS workshop in November 2006. Finally, many outreach and educational activities are being promoted.

A. Stepanov (with V. Obridko), Russia and Eastern Europe, showed many examples of ground-based facilities that are making high quality optical, spectral and radio observations of the Sun and heliosphere. Some of the largest specialized radio antenna systems in the world are in this region including Ratan 600, the Big Pulkova radio telescope and the SSRT. There are also a host of space missions both in operation and being planned. These include Photon, the next in the series of Coronas missions, to be launched late in 2007. An educational website is being organized. The IHY in Russia will be featured in Moscow in October 2007 starting with events celebrating the launch of Sputnik on 4 October 1957. Worldwide this is called the World Space Week 2007 and purports to be the largest public space event in world history, with celebrations in over 50 nations commemorating the 50th anniversary of the Space Age. The Russian IHY group is planning a related IHY meeting in Moscow 8-14 October 2007.

B. Thompson, IHY Director of Operations and Website Coordinator, presented details about the IHY website and the CIPs. She noted that over 45 CIPs have already been proposed. Thompson also leads the IGY Gold (History) program that recognizes scientists around the world who were active in IGY in 1957. There are now more than 50 IHY Gold recipients.

C. Rabello-Soares, IHY Education and Public Outreach Coordinator, presented the many EPO activities being pursued. These start with the IHY/UNBSS instrument program which provides wonderful and varied opportunities for EPO activities in developing countries. The IHY outreach program is dedicated to bringing heliophysics education to all the people of the world. Its goals are to assist in increasing the visibility and accessibility of existing programs, providing greater international exposure for existing programs, promoting new international partnerships, determining the need for multi-lingual adaptations of educational resources and facilitating their translation, and leaving a world-wide legacy of connectivity between those engaged in Education and Outreach efforts related to IHY science. Each IHY National Coordinator for Education and Outreach will act as the liaison between those working on education and public outreach in their country and the IHY secretariat, as well as to the national coordinators of the other nations. Currently 18 National EPO Coordinators have been appointed. We are planning to create a 
resource CD of selected exemplary education and outreach materials from around the world. It will have a companion booklet, and both will be distributed by the UN to all Member States by the end of 2007. An EPO planning meeting, "Globalizing Space Science Education and Outreach", was held during the COSPAR Assembly in Beijing, July 2006. One of the goals is to make IHY multilingual resources available worldwide. Solar eclipses are an excellent way to promote IHY EPO activities. The March 2006 eclipse in Africa and Europe provided a testbed for such activities and was very successful. Viewing stations with EPO materials for viewing eclipses were set up along the path of totality in these countries: Brazil, Ghana, Nigeria, Egypt, Turkey, Georgia and others. An IHY Schools Program is also part of the IHY EPO effort (see below).

David Webb discussed the IAU's involvement in IHY. These activities were mentioned above. Attempts to get IAU support for funding for the IHY Schools and for the IHY/UNBSS workshops was noted. We need to increase our collaborative efforts with other affiliated groups such as CAWSES, SCOSTEP, European COST 724, NASA, and NSF. Webb discussed with M. Gerbaldi, chair of the IAU's ISYA (International School for Young Astronomers) program, the possibility of linking the ISYA and IHY programs, at least in 2007-08, for travel of students and young astronomers to the IHY schools. We also discussed with Peter Willmore the idea of collaborative educational efforts with COSPAR. Since the IAU is a sponsor of the IHY/UNBSS workshops, it is possible to use IAU travel funds to support students to come to those meetings.

The IHY Schools Program is organized by an IHY Schools Committee (ISC) chaired by David Webb. It has been established to provide undergraduate and graduate students with expert training and understanding of heliophysical universal processes. Four main IHY schools are being planned in 2007 for North America (Boulder, CO, USA), Europe/Africa (Trieste, Italy), Latin America (Brazil), and somewhere in the Asian Pacific region. A website for the Schools program is at: <http://www.ihy2007.org/outreach.shtml>. Funding for the schools is an issue both for travel support for students attending the schools and for the support of the schools themselves. The ISC is in the process of developing a uniform curriculum for the schools. Other IHY-related schools are being organized in various countries and will be coordinated as needed by the ISC. The time line of the schools was discussed; they can occur anytime in 2007 but also in 2008 when IHY data sets and results will be better established. The duration and dates of each school will depend on circumstances in the regions/countries where they are held. The dates of the schools should be separated enough in time from each other and also from major international meetings to permit the same key scientists and IHY personnel to attend.

Possible upcoming IHY-related meetings were discussed. The IHY keeps a very good list of past and future meetings on its website at: <http://www. ihy2007.org/events/events.shtml>. Major future IHY meetings include The Second UN/NASA Workshop on the International Heliophysical Year and Basic Space Sciences in Bangalore, India, 27 November - 1 December 2006, the IHY Opening Ceremony and Kickoff Meeting at the United Nations STSC Meeting in Vienna, 19-20 February 2007, the "Open Doors" Day at IHY Observatories and Museums on 10 June 2007, regional meetings in Italy, 24-29 June 2007, and Moscow, 8-14 October 2006, and the third IHY/UN/NASA Workshop in Japan, in November 2006. We will propose an IAU Symposium on IHY science in Greece in 2008. In addition, Division II is sponsoring IAU Symposium No. 247 on "Waves and Oscillations in Solar Atmosphere: Heating and Magnetoseismology" to be held at Porlamar Isla de Margarita, Venezuela, 17-22 September 2007.

On 25 August 2006 at the 82nd EC meeting at the Prague GA, David Webb made a presentation to the EC about IHY activities. These activities are summarized in the final section of the IAU Information Bulletin No. 99 to be published in January 2007.

\section{Discussion of other programs of the Working Group}

Besides the IHY program, the Space Weather WG also includes the International Living with a Star program, the CAWSES WG on Sources of Geomagnetic Activity, and Space Weather studies in China. The CAWSES WG is chaired by Nat Gopalswamy who discussed it at our meeting. This WG has as its objectives to understand how solar events, such as CMEs and high speed streams, impact geospace by investigating the underlying science and developing prediction models and tools. CAWSES has directed three observing campaigns and many workshops have been held. IHY planners are working to collaborate with and not overlap with the CAWSES activities. Toward this end a joint IHY-CAWSES Observation Database is being developed. 
The next major meeting will be the International CAWSES Symposium in Kyoto, Japan, 23-27 October 2007.

J. Wang (with W. Gan) of the Chinese Academy of Sciences described Space Weather studies in China in what is being called a new epoch in Chinese space science. From 2000-2005 the Chinese government initiated a new, well-funded program of space weather research. This has just been extended through 2010. The program has resulted in a large amount of coordinated observations of the Sun and many new revelations from data analysis. Major goals of the next 5-year phase include exploration of the cause-effect chain relationship in space weather initiation and evolution, developing a new scientific framework of space weather forecast and magnetic synoptic meteorology, identifying and attacking the common physical problems in different plasma domains, e.g., 3D magnetic reconnection, shocks and particle acceleration, and creating new concepts for future Chinese space missions. Identified future missions are: SMESE - aimed at observing flares and and Coronal Mass Ejections (CME) for the next solar maximum through wavelength coverage from the gamma rays to the far-infrared; $\mathrm{KuaFu}$ - aimed at continuous surveillance of the Sun and heliosphere and the geomagnetic response to the Suns explosions, and supporting fundamental research in solar and space-plasma physics underlying space weather; and SST - to achieve a breakthrough advance in solar physics through coordinated observations of transient and steady MHD processes with broad wave range, high spatial resolution and continuous temporal coverage. SMESE (Small Mission on Exploration of Solar Eruption) is a joint France-China mission. KuaFu is a Sun-Earth System Explorer project and is concentrated on exploring the complex global behavior of the Sun-Earth system. It will have three spacecraft, one at the L1 point and two in Earth orbit. SST, the Solar Space Telescope, will be characterized by a diffraction-limited optical telescope of 1-meter aperture and a twodimensional polarization spectrometer including a multi-channel birefringent filter.

We ended the session with a discussion about incorporating into the WG information and contacts of the emerging space weather programs and projects that are being developed in other countries and regions. Examples include the fairly extensive programs in Europe, India and South America. As a start David Webb mentioned that we should begin to add this material to the current WG website. He then led a discussion about what should be on the website and what future projects the WG should be involved in.

David F. Webb chair of the Working Group 